\title{
Um estudo experimental sobre empresas virtuais e estratégias de consolidação de marcas perante os consumidores
}

An experimental study on virtual companies and consumer brand consolidation strategies

\author{
Rafael Soares Pedroso $^{\dagger *}$, Anrafel Fernandes Pereira ${ }^{\dagger}$, Margareth Fernandes $^{\dagger}$ \\ Como citar esse artigo. Pedroso, RS; \\ Resumo
} Pereira, AF; Fernandes, M. Um estudo experimental sobre empresas virtuais e estratégias de consolidação de marcas perante os consumidores. Revista Teccen. 2019 Jul/Dez; 12 (2): 94-107.

\begin{abstract}
Hoje em dia, muitas empresas têm sido criadas diretamente no ambiente virtual. Tudo isso devido principalmente as facilidades e comodidades que o meio oferece. Entretanto, ao iniciarem suas atividades, a maioria dessas empresas falham por não estudarem adequadamente o mercado onde estão entrando, e ainda, por adotarem muitas das vezes estratégias erradas na busca pela consolidação de suas marcas nesse mercado tão abrangente e competitivo. Sendo assim, este trabalho apresenta um estudo das estratégias que vem sendo adotadas por algumas empresas virtuais em busca de consolidação de suas marcas no mercado. Para isso, mediu o impacto que essas estratégias estão tendo perante seus clientes, através da aplicação de questionários e analisando os resultados. Como objeto de estudo deste trabalho, algumas empresas e clientes do Estado do Rio de Janeiro, mais especificamente da região Sul-Fluminense foram selecionados. Os resultados iniciais desse estudo são apresentados nesse artigo

Palavras-Chave: Empresas Virtuais, Internet, E-commerce, Marketing Estratégico.
\end{abstract}

\begin{abstract}
Nowadays, many companies have been created directly in the virtual environment. All this due mainly to the facilities and amenities that the medium offers. However, when they begin their activities, most of these companies fail to adequately study the market they are entering, and often to adopt wrong strategies in the search for consolidation of their brands in such a comprehensive and competitive market. Thus, this work presents a study of the strategies that have been adopted by some virtual companies in search of consolidation of their brands in the market. To do so, it measured the impact these strategies are having on their clients, through the application of questionnaires and analyzing the results. As a study object of this study, some companies and clients from the State of Rio de Janeiro, more specifically from the Sul-Fluminense region were selected. The initial results of this study are presented in this article.
\end{abstract}

Keywords: Virtual businesses, Internet, e-commerce, Strategic marketing.

\section{Introdução}

Atualmente, um crescente número de empresas tem sido criado diretamente no ambiente virtual. Essas empresas oferecem os mais variados tipos de produtos e serviços, porém muitas vezes competem com grandes lojas do mercado tradicional, que também possuem suas lojas virtuais. De acordo com um estudo encomendado pelo Google junto à Forrester Research, as vendas na internet no Brasil devem atingir a marca de 84,7 bilhões até 2021. O valor é 47,5\% maior do que os 57,4 bilhões projetados para 2018 (Casagrande, 2018).

Muitas empresas ao iniciarem suas atividades falham por não estudarem adequadamente o mercado ondeestão entrando, relegandoa possibilidade deanalisar cases de sucesso que poderão trazer direcionamentos para esses novos negócios e evitar erros comuns que podem levar até mesmo ao fim prematuro de suas atividades. É importante procurar entender ainda o comportamento do consumidor, definir um público alvo e estar alinhado com suas expectativas.

Este artigo busca identificar as estratégias e métodos que esses pequenos empreendedores têm implementado para buscar a consolidação de suas marcas nesse mercado tão abrangente e competitivo, bem como identificar as vantagens e desvantagens competitivas que essas empresas apresentam em relação às grandes concorrentes do mercado tradicional. Buscase ainda, enumerar os tipos de produtos mais buscados pelos consumidores nesse ambiente, além de identificar possíveis novos mercados ainda não explorados.

Afiliação dos autores:

† Universidade de Vassouras, Curso de Pós-Graduação Lato Sensu em Gestão Estratégica de Negócios em Tempos de Mudanças - MBA EXECUTIVO, Vassouras, RJ, Brasil

* Email para correspondência: rafaelpedroso.ti@gmail.com 
Para isso, um estudo, em forma de questionário, foi preparado e realizado. Foram analisados os pontos mais importantes considerados pelos consumidores ao efetuar uma compra no ambiente da internet. Por fim, foram avaliadas ainda a importância da logística e do tempo de atendimento como fatores cruciais de sucesso desses negócios, a variedade de produtos como uma vantagem competitiva, a medição do nível de burocracia e sua relação com o nível de dificuldade da gestão desses empreendimentos, a busca por produtos personalizados como diferencial competitivo e as ações de pós-venda como estratégia eficiente ou não na fidelização dos clientes.

Este artigo está organizado da seguinte maneira: na seção 2 é apresentada a fundamentação teórica do trabalho, destacando o perfil dos e-consumidores, as estratégias que mais vem sendo utilizadas para aumentar as vendas online, métodos de medição da lealdade dos clientes, o perfil do consumidor do futuro, onde a integração entre os meios físico e virtual serão cada vez maiores, um panorama recente do mercado de e-commerce, medido em 2017 e a apresentação de pontos em destaque do Relatório Webshoppers de 2019; a seção 3 apresenta os materiais e métodos, ou seja, explica como foi feito o planejamento e a execução da pesquisa; na seção 4 os resultados são apresentados e discutidos; na seção 5 são feitas as considerações finais, incluindo a proposição de estudos futuros; por fim, na seção 6 são apresentadas as referências nas quais o estudo foi embasado.

\section{Fundamentação Teórica}

\section{Perfil Dos Consumidores}

Tambémchamado e-consumidor, osconsumidores online são classificados de diversas formas por vários autores (De Almeida et al., 2012; Nascimento, 2011).

Para Hortinha (2002 apud Nascimento, 2011), os mercados consumidores são classificados de acordo com quatro diferentes critérios de segmentação: critérios geográficos (tipo de região), demográficos (sexo, idade, dimensão da família), sociais e econômicos (rendimento, nível de educação, religião); critérios de personalidade e estilo de vida (atividades, interesses e valores); critérios de comportamento relativamente ao produto/ serviço (refere-se ao grau de utilização e lealdade à marca); e critérios de atitude psicológica relativamente ao produto/serviço (da mesma forma que o critério de comportamento).

Para Modahl (2000 apud Nascimento, 2011), os consumidores devem ser estudados através de uma combinação dos aspectos demográficos e psicográficos. Dessa combinação surgem as dimensões de renda (alta ou baixa), postura diante da tecnologia (otimista ou pessimista), e motivação principal (carreira, família ou entretenimento). Daí são obtidos subgrupos classificados da seguinte forma: os que possuem maior renda e mais otimismo são chamados de adotantes iniciais. Os que têm como motivação principal a carreira, são chamados acelerados. $E$ aqueles que se motivam pelas necessidades familiares e tem alta renda e otimismo, são chamados seguidores da nova era (Catalani, 2006 apud Nascimento, 2011).

Num estudo da consultoria Mckinsey (apud Nascimento, 2011) são seis ascategoriasdeconsumidores online: simplificadores (gostam de informações sobre serviços confiáveis e respondem positivamente a estímulos que indiquem facilidade maior no ambiente online que no off-line) - segundo a pesquisa, responsável por $50 \%$ de todas as transações na web; surfadores (usam a internet para diversos fins e movem-se muito rápido entre diversos sites - responsáveis por 32\% do tempo consumido na rede e atraídos por novidades e conteúdos diversos e atualizados); negociadores (valorizam bons negócios, visitadores de leilões pela internet, por exemplo - atraídos principalmente pelo lado emocional); conectadores (utilizam a web basicamente para se conectarem com outras pessoas através de $e$ mails e redes sociais - de perfil mais iniciante e com poucas finalizações de compras online); rotineiros (usam a internet principalmente pelo conteúdo oferecido e gastam mais de $80 \%$ do seu tempo online em seus sites preferidos); e esportistas (mesmo comportamento dos rotineiros, porém costumam frequentar sites de esportes e entretenimento).

Segundo pesquisa IBOPE de 2001 (apud Nascimento, 2011), a segmentação dos consumidores ficou da seguinte forma: cuidadosos (maior preocupação com assuntos financeiros e gastronômicos), caseiros (utilizadores moderados da internet, dedicam mais tempo a casa e se consideram religiosos tradicionais), despreocupados (não se importam com assuntos de saúde e alimentação, usuários frequentes da internet), reacionários (machistas e preferem ser conduzidos) e típicos (perfil médio do internauta).

Pesquisas como a TG.Net do IBOPE (2010 apud Nascimento, 2011) demonstram que há uma predominância entre os consumidores online nas classes $\mathrm{AB}$, correspondendo a $61 \%$, ante os $31 \%$ da classe $\mathrm{C}$ e $4 \%$ das classes DE.

Ao analisar a faixa etária desses consumidores, destacam-se os públicos de 25 a 34 anos (29\%) e 35 a 44 anos (27\%), segundo pesquisa TIC Domicílios (2009 apud Nascimento, 2011).

O IBOPE (2010 apud Nascimento, 2011) aponta que há uma leve predominância do público masculino (54\% contra $46 \%$ do público feminino). 
ESTRATÉGIAS PARA O AUMENTO DE VENDAS ONLINE

De acordo com Casagrande (2018, p. 48-50), existem sete pontos a serem observados para que se obtenha sucesso nas vendas digitais: a escolha de uma boa plataforma de hospedagem da loja, o investimento empreendido nessa plataforma, o investimento na experiência (navegabilidade) do usuário na página, uma boa logística de entrega dos produtos, os prazos de entrega, possuir formas de recebimento diversificadas, e o planejamento de ações de marketing (promoções, sazonalidades, descontos, entre outros).

O investimento em uma plataforma SaaS (Software as a Service) pode envolver um custo fixo mensal, porcentagem em vendas ou pode até mesmo ser gratuita, porém é preciso avaliar se os recursos disponíveis irão suprir as necessidades da loja e permitir seu crescimento. Trocar de plataforma pode ser muito custoso, por isso é recomendável comparar recursos, verificar reviews de outros usuários e calcular a relação custo $\mathrm{x}$ benefício.

Fatores como posicionamento do caixa, o tempo de carregamento da página, a qualidade das fotos dos produtos e até mesmo a cor dos botões de venda influenciam na navegabilidade e consequentemente no sucesso das vendas (Jacobsen apud Casagrande, 2018). De acordo com Jacobsen (2018 apud Casagrande, 2018, p. 49), "Existe uma estatística que diz que $40 \%$ dos usuários abandonam um site caso ele demore mais que três segundos para carregar, por exemplo”.

Além disso, possuir um bom sistema de entrega também é um fator primordial, porém somente com um volume maior é possível contratar empresas especializadas como grandes transportadoras e startups em detrimento dos Correios, que geralmente são a primeira opção, porém costumam trazer alguns transtornos, como ocasionais greves de funcionários, por exemplo. É preciso ainda oferecer mais de uma forma de entrega, como por exemplo, agendamento e entrega expressa, e zelar pelos prazos. Atentando também para os custos que tais serviços irão trazer ao negócio (Mattos apud Casagrande, 2018).

Possuir mais de um parceiro para realizar os pagamentos também é um fator que contribui para o sucesso das vendas, e existem várias opções no mercado, tais como a PagSeguro do UOL, a plataforma Mercado Pago, o Paypal e o Moip, cada uma com diferentes taxas e prazos de recebimento, cabendo ao lojista avaliar qual das opções atende melhor às suas necessidades.

Finalmente, o último ponto observado são as ações de marketing. Especialistas afirmam que é possível aumentar o faturamento mesmo com baixo investimento, porém fazendo um planejamento adequado e aproveitando os períodos sazonais como dia das mães, dia dos namorados, Black Friday, Natal etc, além de promoções que a empresa queira criar (Casita apud
Casagrande, 2018).Além disso, existem pequenas táticas para atrair o cliente nas redes, como o uso de palavras-chave e propagandas no Google e redes sociais.

Após o seguimento do cliente à empresa, promover pequenos engajamentos como números, resenhas positivas e a reputação do produto na mídia. Na sequência, criar o senso de urgência, através de descontos relâmpago e falta do produto em estoque, por exemplo. E por último, estimular que o cliente avalie a compra. Tudo isso, colabora para o desenvolvimento de um negócio de forma positiva e impactante (Araujo et al., 2013).

\section{Lealdade Do Consumidor}

De acordo com Oliver (1999 apud De Almeida et al., 2012, p. 5):

Lealdade à marca é definido como um profundo comprometimento em recomprar ou utilizar novamente um produto ou serviço preferido consistentemente no futuro, causando, portanto, repetição de compras de uma marca ou conjunto de marcas, indiferente às influências situacionais e esforços de marketing, que possuam o potencial de causar um comportamento de mudança, de troca.

Segundo Aaker (1998 apud De Almeida et al., 2012), a lealdade dos consumidores agrega valor à marca de diversas maneiras, como por exemplo reduzindo os custos de marketing, alavancagem comercial, atração de novos consumidores e tempo maior para resposta aos concorrentes. Trata-se de uma importante base para o desenvolvimento de uma vantagem competitiva e sua gestão pode ser considerada um grande desafio.

Porém para que a lealdade ocorra é necessário que o cliente tenha a crença de que o produto ou serviço em questão é (ou continua a ser) a melhor alternativa do mercado (Oliver, 1999 apud De Almeida et al., 2012).

Diante desse cenário, vários pesquisadores têm desenvolvido e testado inúmeros modelos de lealdade na tentativa de melhor compreensão da natureza dos seus ocasionadores, como por exemplo, o modelo norueguês ampliado (NCSB Ampliado) proposto por Johnson, Gustafsson, Andreassen, Lervik e Cha (2001) que considera como antecedentes da lealdade a imagem, o comprometimento afetivo e o comprometimento calculado. Imagem refere-se à reputação da empresa no mercado, comprometimento afetivo referese ao apego emocional à empresa, identificação, compartilhamento de valores, dedicação e semelhança (Fullerton, 2003 apud De Almeida et al., 2012), enquanto que o comprometimento 
calculado refere-se aos aspectos econômicos, sociais e de status da relação cliente-empresa (Gruen et al., 2000 apud De Almeida et al., 2012). De Almeida et al. (2012) considera ainda o construto confiança como mais um desses antecedentes a ser considerado, já que tratase da variável mais aceita como base para a interação humana ou relações de troca, ou seja, a crença de que a outra parte irá cumprir com suas obrigações sem agir oportunisticamente (Gundlach \& Murphy, 1993 apud De Almeida et al., 2012).

\section{O Consumidor Do Futuro}

Segundo Casagrande (2018, p. 71), “A evolução do conceito de multicanal tem sido uma estratégia certeira entre as empresas brasileiras. A proposta é permitir que o cliente transite entre o on e o off-line de uma marca de maneira natural e fluida”, ou seja, de acordo com previsões de especialistas, a tendência é que a diferença entre as lojas físicas e virtuais desapareça. Será possível, por exemplo, um cliente procurar por um produto em um canal on-line, saber em quais lojas próximas o produto está disponível, e decidir se irá buscá-lo pessoalmente ou se irá recebê-lo em casa.

De acordo com Pessoa (2018), “[...] outras tecnologias que ainda são restritas, como realidade virtual e inteligência artificial, terão forte presença no varejo”. A tendência é que a presença das lojas físicas diminua ao longo dos anos, porém sem perder a sua importância por completo. Essas lojas irão funcionar mais como vitrines, e haverá ainda a presença das chamadas lojas temporárias, que serão utilizadas pelas marcas em eventos, unindo integralmente o uso da internet com a presença física. Dessa forma será possível reforçar a marca, reforçar a experiência do consumidor e reduzir custos com locação física.

O uso dos smartphones tende a crescer ainda mais, com as empresas otimizando seus sites e investindo em aplicativos para facilitar as compras (PESSOA, 2018). Pequenas empresas ao implementarem a cultura do multicanal podem encontrar uma facilidade de controle maior do que grandes concorrentes, porém irão ter uma abrangência menor, e também precisam planejar muito bem que canais irão operacionalizar, visto que os custos podem ser onerosos para a empresa.

Com isso, percebe-se que o perfil esperado do consumidor do futuro seja de alguém que exigirá cada vez mais comodidade e integração entre os diferentes canais de vendas das marcas as quais consomem.

\section{Panorama Do Mercado (E-Commerce Trends 2017)}

Em uma pesquisa de mercado realizada em março de 2017 entre consumidores, trabalhadores de e-commerce e pessoas que nunca fizeram compras online, é possível perceber que dentre os participantes, apenas $1,2 \%$ nunca efetuaram compras pela internet. O principal fator impeditivo apontado foi a vontade de experimentar e ver o produto pessoalmente antes de comprar (Pesquisa e-commerce trends, 2017).

Já os fatores apontados como motivos para comprar em e-commerce, foram preços mais baratos que os das lojas físicas $(74,2 \%)$, facilidade de comparar preços e produtos (73,3\%) e mais comodidade (69,6\%).A figura 1 apresenta esse panorama.

Ao serem perguntados a respeito do dispositivo utilizado para realizarem as compras, 44,3\% disseram utilizar o smartphone, o que confirma a importância em ter um site com boa navegabilidade e responsivo em qualquer plataforma. Segundo os gerentes entrevistados, 97,9\% dos clientes já abandonaram um carrinho de compras. Entre os principais motivos está o valor do frete, com 73,8\%, por exemplo. Na figura 2 é possível perceber os outros motivos que levaram clientes a abandonarem o carrinho de compra em uma compra online.

Ao serem perguntados sobre como descobrem novas lojas, os entrevistados responderam utilizar principalmente redes sociais $(69,4 \%)$ e o Google (66,5\%). Na Figura 3, a busca orgânica no Google aparece em segundo lugar, por exemplo.

Vale ressaltar aqui que, dentre as redes sociais mais utilizadas, a primeira foi o Facebook (96,6\%), seguida pelo Instagram (87,2\%), Linkedin $(75,6 \%)$ e You Tube (68\%).

A respeito das estratégias de marketing utilizadas e que trazem maior resultado, os blogs foram bastante citados como ferramentas para atrair tráfego para a loja, convencer o cliente da compra, aumentar o reconhecimento do negócio e ganhar a confiança do usuário, dentre outras vantagens. Apesar disso, apenas 43,2\% dos lojistas disseram possuir um blog para seus negócios. Ao comparar o tráfego das lojas quepossuem blog com as que não possuem, é possível perceber o número de visitas bem maior no primeiro caso.

O aumento do número de visitas se dá pelo trabalho de marketing de conteúdo e estratégias de SEO (Search Engine Optimization, ou otimização para mecanismo de pesquisa) inserido nesses blogs. Dentre os entrevistados, $77,9 \%$ dos lojistas disseram empregar técnicas de SEO. O principal elemento utilizado são as palavras-chave com $83,5 \%$ das respostas.

Dentre os principais desafios, foram apontados o aumento da taxa de conversão no site $(68,9 \%)$, o aumento do volume de vendas (68,6\%), o aumento do tráfego do site $(46,3 \%)$ e a fidelização dos clientes (34,7\%).

Tudo isso evidencia a mudança do mercado que estamos vivendo e deixa mais claro ainda como os novos consumidores estão mudando a sua maneira de se 
Motivos que levaram a não comprar em e-commerces

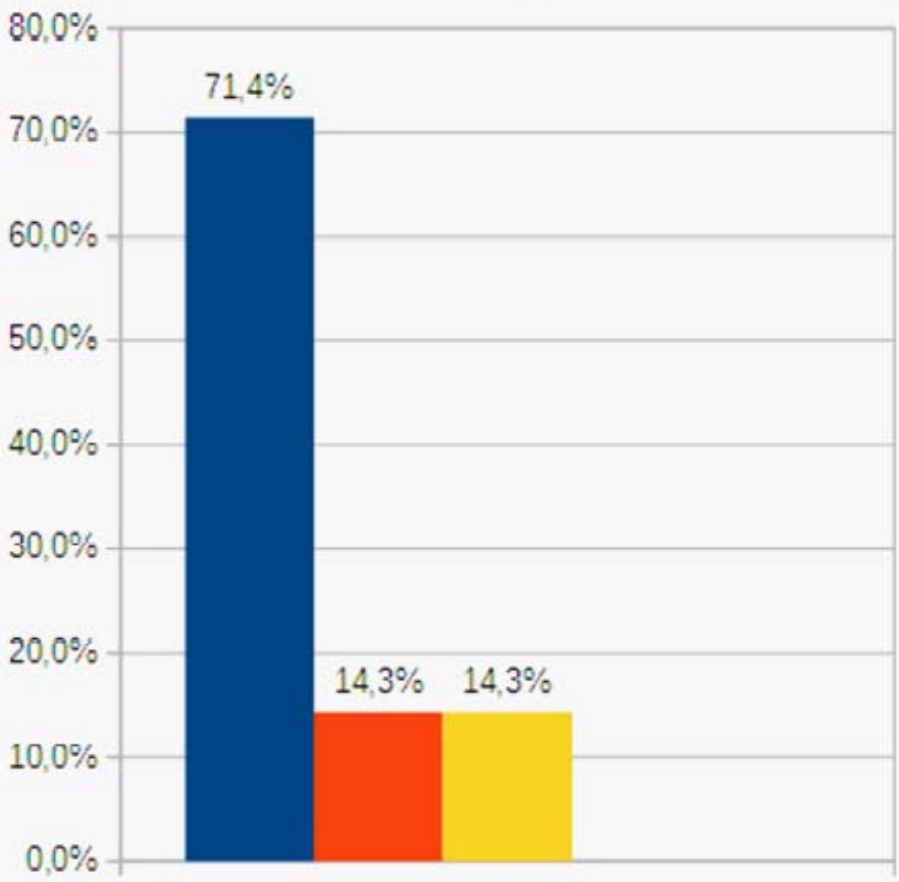

Vontade de experimentar e ver o produto pesscalmente antes de comprar

n Considerar as taxas de frete muito caras

- Nào confíar

- Não existir a possibilidade de negociar preço

- Tempo de entrega muito demorado

Figura1. Motivos que levaram a não comprar em e-commerces

Fonte: O autor (adaptado de Pesquisa E-Commerce Trends 2017).

\section{PRINCIPAIS MOTIVOS PARA ABANDONO DE CARRINHO}

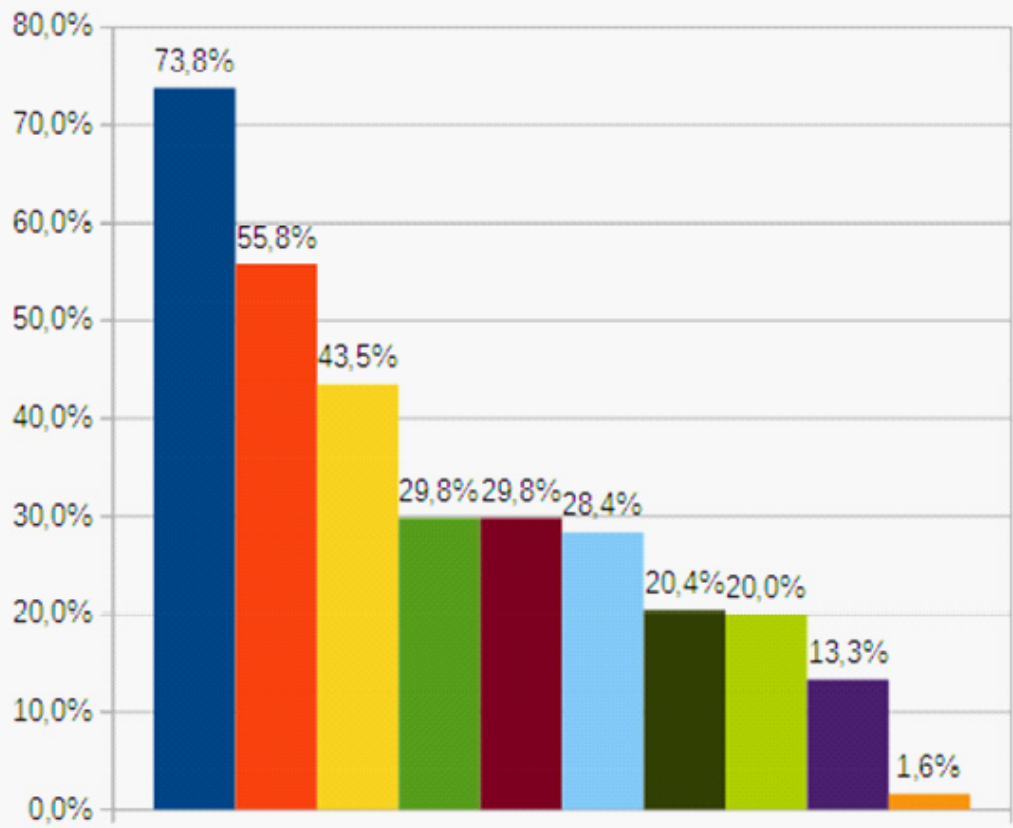

-FRETE MUITO CARO

- REFLETIR SOBRE A NECESSIDADE DE COMPRA

- O PRAZO DE ENTREGA ERA MUITO DEMORADO

- INSEGURANÇA QUANTO AO

PAGAMENTO

-DESEJO DE APENAS DESCOBRIR

O VALOR DO FRETE

= NÄO APRESENTAVA A OPCCAO DE PAGAMENTO DESEJADA

- CHECKOUT CONFUSO

EXIGIA A CRIACCẢO DE UMA NOVA CONTA

- NÄO TINHA DESCONTO

IOUTRA

Figura 2. Motivos de abandono de carrinho 


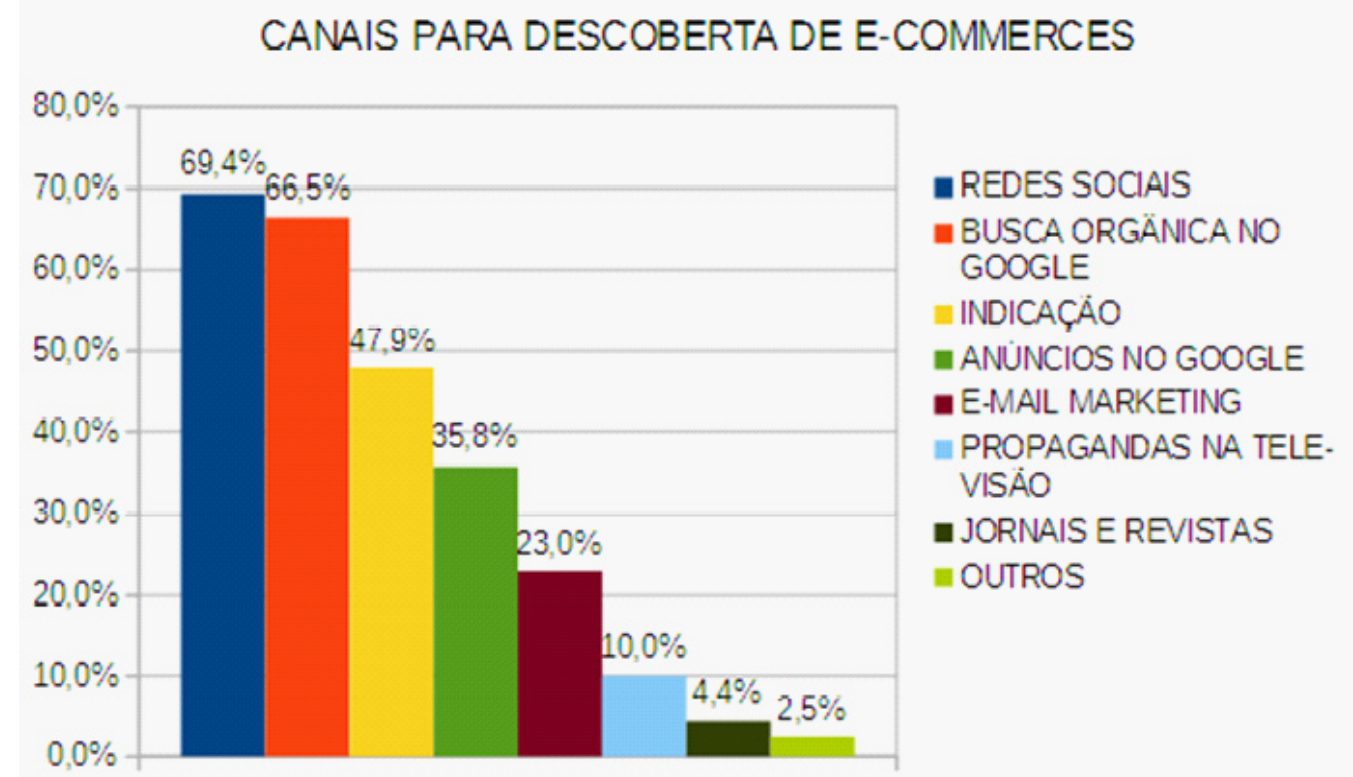

Figura 3. canais de descoberta de e-commerces

Fonte: O autor (adaptado de Pesquisa E-Commerce Trends 2017).

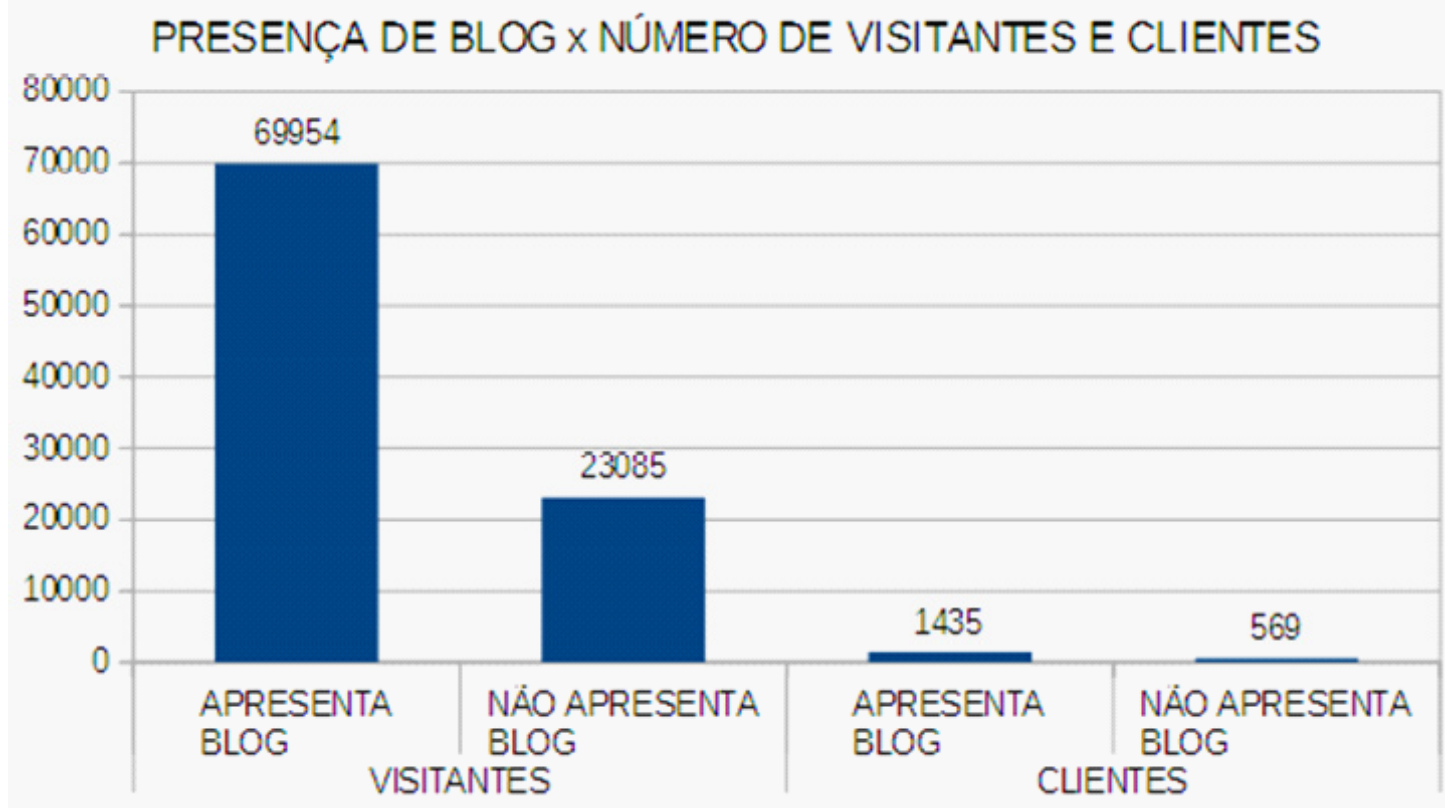

Figura 4. lojas com blog x número de visitas e clientes 


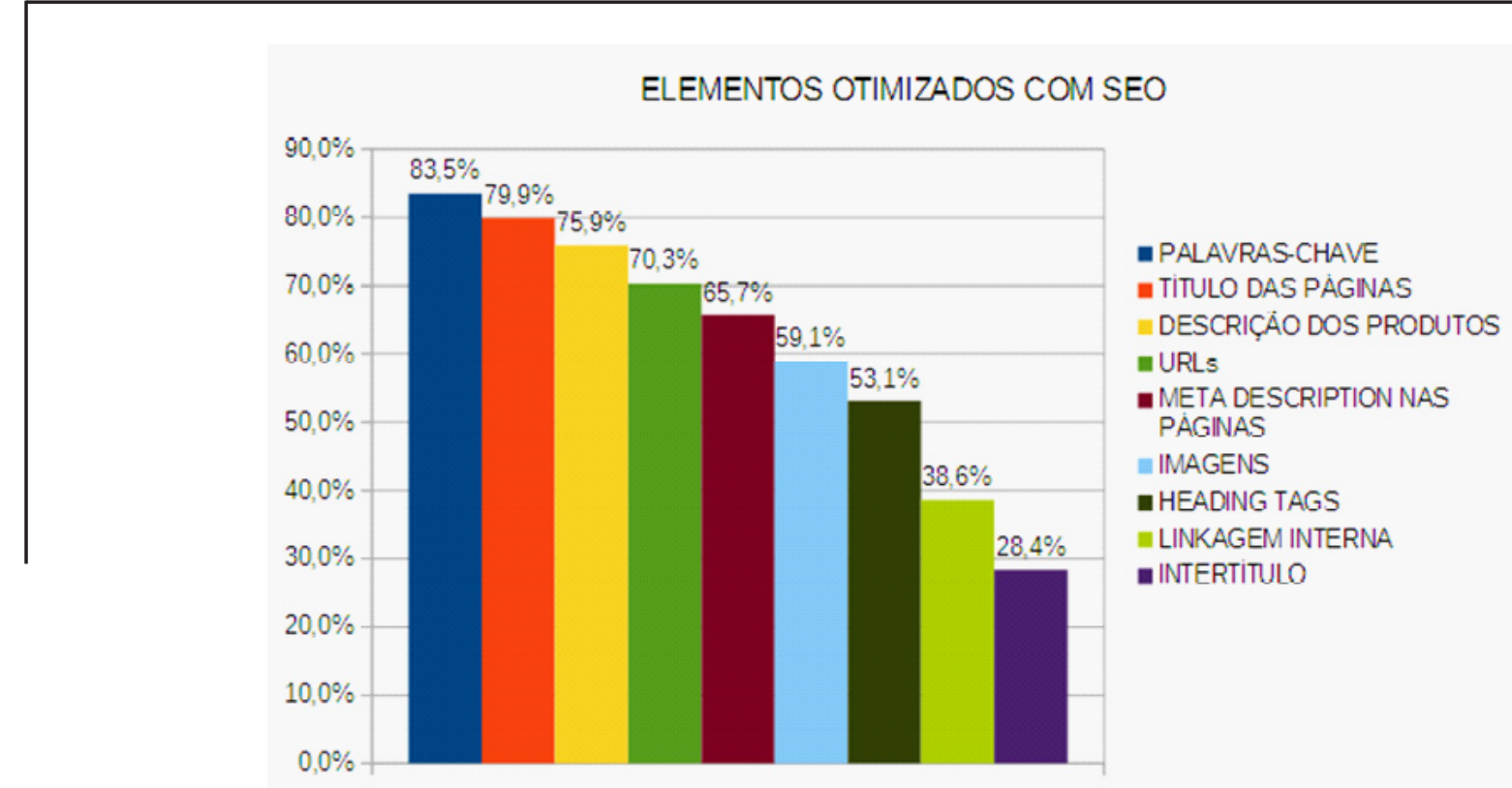

Figura 5. Elementos otimizados com SEO

relacionar e acessar as lojas e produtos que tem interesse. Na seção seguinte são apresentados os materiais e métodos utilizados nesse estudo para responder ao problema levantado.

\section{Relatório Webshoppers 2019}

O Relatório Webshoppers é um relatório sobre o e-commerce no Brasil com grande credibilidade, realizado pela Ebit-Nielsen. A coleta anual de informações para compor esse relatório corresponde sempre ao ano anterior, ou seja, a 39ª edição corresponde aos dados coletados no ano de 2018. Os resultados do último ano foram positivamente surpreendentes e promissores, fechando com um crescimento de vendas na casa dos dois dígitos (12\%).

O índice que mais chamou a atenção foi o aumento das vendas no $m$-commerce, que são compras realizadas através de dispositivos móveis, que somente em janeiro de 2019 teve um crescimento de 42,8\%. Enquanto o ecommerce teve um crescimento de $12 \%$ em 2018, o mcommerce durante o mesmo período apresentou um crescimento de $41 \%$.

O faturamento total chegou à casa dos $\mathrm{R} \$ 53,2$ bilhões, com 123 milhões de pedidos, sendo 31,3\%(R\$ 16,7 bilhões) relativos às vendas através de dispositivos móveis. Esses números revelaram também, juntamente com o avanço do m-commerce, a inserção de 10 milhões de novos clientes no mercado, que fizeram sua primeira compra on-line, o que leva a constatação de que os dispositivos móveis vêm se tornando uma importante via de democratização do e-commerce, possívelatravés da expansão do mercado de smartphones e do acesso à banda larga.

A categoria de produtos mais pedida foi a de Perfumaria, Cosméticos e Saúde, com 16,4\% dos pedidos, seguida por Moda e Acessórios, com 13,6\%, por Casa e Decoração, com 11,1\%, e Eletrodomésticos, com $10,6 \%$.

Com relação ao faturamento, a categoria campeã foi a de Eletrodomésticos, com 19,6\%, seguida por Telefonia e Celulares, com 18\%. Casa e Decoração, Informática e Eletrônicos são as outras categorias que completam as cinco maiores em faturamento.

Algumas categorias merecem destaque pelo crescimento apresentado no período, como Esporte e Lazer, com 10\% dos pedidos, Alimentos e Bebidas, com 23\%, e Livros, Assinaturas e Apostilas com crescimento maior especificamente na região nordeste.

Cada um dos semestres do ano teve um aumento de vendas relativo a alguma data comemorativa, o que destaca a importância de um planejamento prévio para essas datas. Lojas que não se preparam devidamente para o aumento da procura nessas datas podem perder a credibilidade perante os consumidores.

A expectativa para 2019 nessas datas é que o sucesso permaneça e até aumente.

O frete grátis também foi um fator impulsionador de vendas, lojas que o adotaram principalmente em datas sazonais puderam desfrutar de boas vendas.

Além disso, a possibilidade de devolução do dinheiro no caso de problemas com o produto foi outro fator de impulsão nas vendas.

As compras feitas por brasileiros em e-commerces internacionais tiveram queda no ano de 22,2\%, 


\section{Crescimento em número de pedidos do M-Commerce}

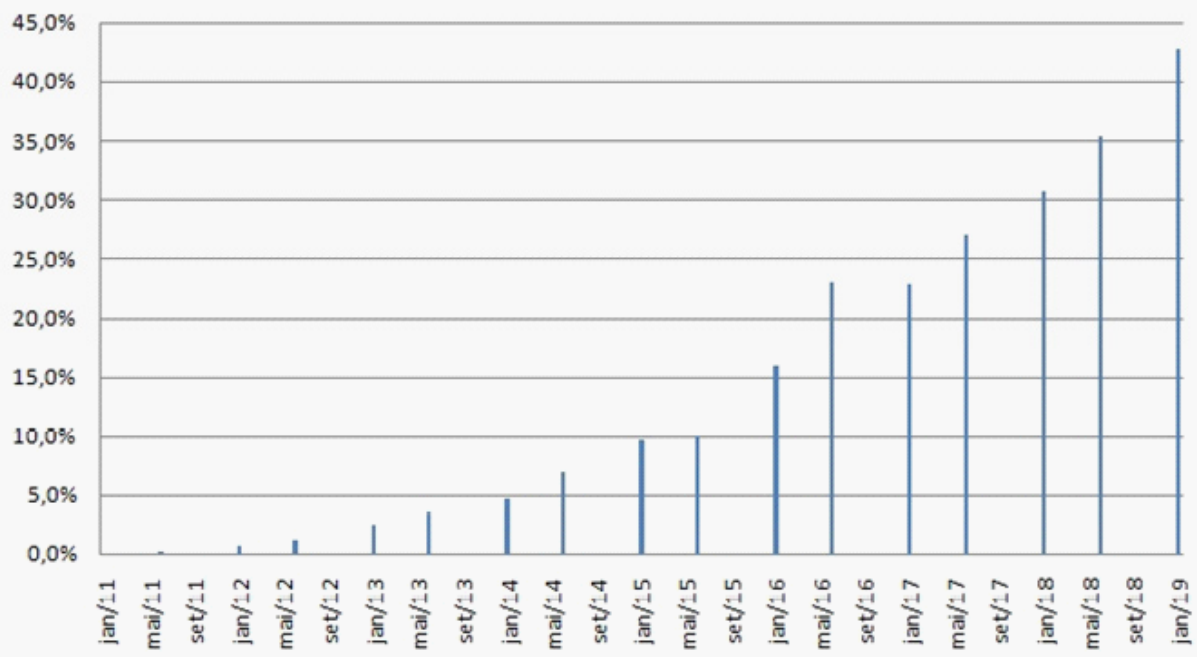

Figura 6. Crescimento em número de pedidos do E-Commerce

Fonte: O autor (adaptado de Pesquisa E-Commerce Trends 2017).

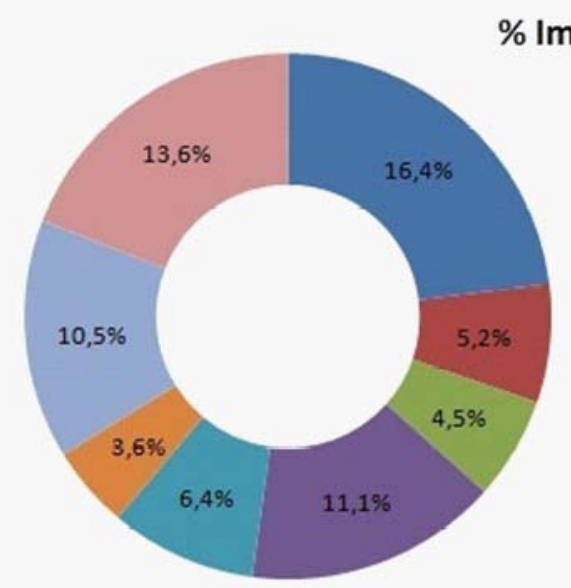

\% Importância em pedidos

Variação do número de pedidos

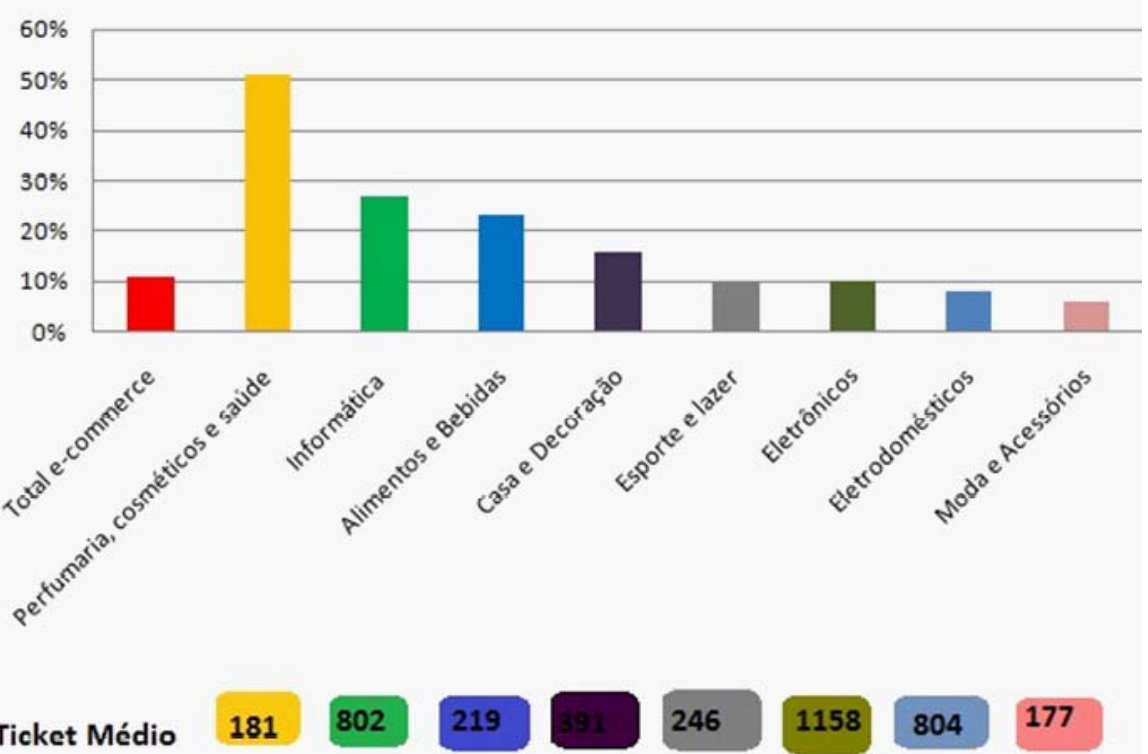

Figura 7. Crescimento de pedidos em categorias de ticket médio baixo 
Tabela 1. As Principais Datas Sazonais / Comemorativas Brasil

\begin{tabular}{|c|c|c|c|c|c|c|c|c|}
\hline $\begin{array}{c}\text { Datas } \\
\text { Comemorativas }\end{array}$ & Período & Pedidos & Faturamento & $\begin{array}{l}\text { Tíquete } \\
\text { Médio }\end{array}$ & $\begin{array}{l}\text { Variação } \\
\text { Pedidos }\end{array}$ & $\begin{array}{l}\text { Variação } \\
\text { Financeira }\end{array}$ & $\begin{array}{l}\text { Share } \\
\text { Pedidos } \\
\text { do Ano }\end{array}$ & $\begin{array}{c}\text { Share } \\
\text { Financerro } \\
\text { do Ano }\end{array}$ \\
\hline $\begin{array}{l}\text { Dia do } \\
\text { Consumidor }\end{array}$ & $14 / 03 / 2018$ & $521 \mathrm{mil}$ & $\begin{array}{l}\text { RS219 } \\
\text { Milhões }\end{array}$ & $\mathrm{R} \$ 420$ & $24 \%$ & $8 \%$ & $0,4 \%$ & $0,4 \%$ \\
\hline Dia das Mães & $\begin{array}{c}28 / 04 \mathrm{a} \\
12 / 05 / 2018\end{array}$ & $4,6 \mathrm{mi}$ & $\begin{array}{l}\text { R\$2,11 } \\
\text { bilhões }\end{array}$ & $\mathrm{R} \$ 459$ & $2 \%$ & $12 \%$ & $3,7 \%$ & $4,0 \%$ \\
\hline $\begin{array}{c}\text { Dia dos } \\
\text { Namorados }\end{array}$ & $\begin{array}{c}28 / 05 \mathrm{a} \\
11 / 06 / 2018\end{array}$ & $3,8 \mathrm{mi}$ & $\begin{array}{l}\text { R\$1,77 } \\
\text { bilhões }\end{array}$ & $\mathrm{R} \$ 464$ & $-6 \%$ & $4 \%$ & $3,1 \%$ & $3,3 \%$ \\
\hline Dia dos Pais & $\begin{array}{c}28 / 07 \mathrm{a} \\
11 / 08 / 2018\end{array}$ & $5,1 \mathrm{mi}$ & $\begin{array}{l}\text { R\$2,09 } \\
\text { bilhões }\end{array}$ & $\mathrm{R} \$ 409$ & $22 \%$ & $8 \%$ & $4,2 \%$ & $3,9 \%$ \\
\hline Dia das Crianças & $\begin{array}{c}27 / 09 \mathrm{a} \\
11 / 10 / 2018\end{array}$ & $4,8 \mathrm{mi}$ & $\begin{array}{l}\text { R\$1,97 } \\
\text { bilhões }\end{array}$ & $\mathrm{R} \$ 409$ & $8 \%$ & $6 \%$ & $3,9 \%$ & $3,7 \%$ \\
\hline Black Friday & $\begin{array}{c}22 \text { e } \\
23 / 11 / 2018\end{array}$ & $4,3 \mathrm{mi}$ & R\$2,6 bilhões & R\$608 & $13 \%$ & $23 \%$ & $3,5 \%$ & $4,9 \%$ \\
\hline Cyber Monday & $26 / 11 / 2018$ & $752 \mathrm{mil}$ & $\begin{array}{l}\text { R\$372 } \\
\text { milhões }\end{array}$ & $\mathrm{R} \$ 494$ & $4 \%$ & $20 \%$ & $0,6 \%$ & $0,7 \%$ \\
\hline Natal & $\begin{array}{c}10 / 12 \text { a } \\
24 / 12 / 2018\end{array}$ & $5,3 \mathrm{mi}$ & $\begin{array}{l}\text { R\$2,54 } \\
\text { bilhões }\end{array}$ & $\mathrm{R} \$ 475$ & $4 \%$ & $18 \%$ & $4,4 \%$ & $4,8 \%$ \\
\hline
\end{tabular}

concentrando a maior parte das compras no território nacional.

O ticket médio das compras realizadas internacionalmente em 2018 foi menor que nos anos de 2015 e 2017 (de US\$ 35,46 para US\$ 36,79), apresentando diferença de $5,2 \%$, um ticket médio de US\$ 30,48.

Através dos números apresentados pela pesquisa, as expectativas são boas para quem deseja iniciar um novo negócio ou investir em seu crescimento em 2019.

Para tanto, alguns aspectos merecem ser observados com mais atenção, como umainterface com o consumidor cada vez mais fácil, simples e rápida; entender o perfil dos consumidores acessando o canal e quais produtos ofertar; investir na experiência do consumidor, desde a intenção de compra até o pós- venda; a coexistência dos canais on-line e off-line, sem sobrepor suas propostas de valor.

\section{Materiais e Métodos}

Para responder ao problema levantado nesse trabalho, um estudo foi realizado e o protocolo definido para a sua realização, bem como os seus resultados e análise são apresentados a seguir. O estudo realizado, diz respeito a entrevistas realizadas através de questionário com dois públicos distintos, são eles os consumidores finais e pequenos empresários. O escopo do trabalho fica mais claro durante a apresentação do protocolo do estudo. 


\section{Frete Grátis}

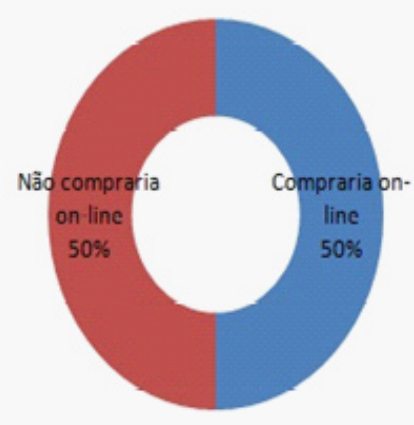

Figura 8. Disposição dos consumidores em fazer compras on-line

\section{Devolução do Dinheiro}

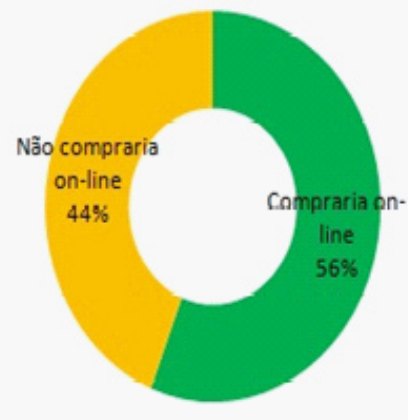

Fonte: O autor (adaptado de Relatório Webshoppers 2019

\section{Planejamento Do Estudo Realizado}

Foram desenvolvidos dois questionários, com $13 \mathrm{e}$ 8 questões, respectivamente, entre elas questões objetivas e dissertativas. O primeiro questionário foi direcionado para empresários, proprietários de empresas virtuais na região Sul Fluminense no Estado do Rio de Janeiro. O segundo questionário foi voltado para clientes diversos dessas e outras empresas, também utilizando a mescla de perguntas abertas e fechadas como no primeiro.As perguntas foram elaboradas com base na percepção de mercado dos autores e através da observação dos dados levantados durante a fundamentação teórica deste estudo e sua respectiva relevância em relação aos seus objetivos. O público em questão foi buscado através de contatos pessoais e/ou virtuais, privilegiando sempre o perfil de pequeno empreendedor, no caso do primeiro grupo, e seus respectivos compradores, contactados através dos próprios empresários e incentivados a responderem o questionário. Houve certa dificuldade em alcançar um grande número de respostas, devido ao curto prazo para conclusão do estudo e disponibilidade do público em respondê-lo.

\section{Objetivo Da Entrevista}

Os objetivos desejados através da aplicação desses formulários foram: (i) em relação às empresas, identificar os tipos de produtos vendidos e seus públicos alvo, o raio de abrangência de suas vendas, o tempo da empresa no mercado e na internet, e principalmente a percepção desses empresários em relação à preferência por parte dos clientes ao seu negócio, às ferramentas de marketing empregadas e sua eficiência, além do nível de dificuldade encontrado para legalizarem seus negócios, para assim confirmar se realmente são simples de serem geridos; e (ii) em relação aos clientes buscou-se traçar um perfil do consumidor a partir de sua idade e gênero, os produtos mais buscados por esses clientes através da internet, bem como os itens considerados por eles como os mais importantes que um site de uma loja virtual deva possuir, e o que os faz optar por uma compra em uma loja que não seja considerada consagrada em detrimento das grandes concorrentes. Também se buscou identificar algum produto que foi procurado por algum desses clientes e não foi encontrado. Por fim, procurou-se identificar o tipo de ação de marketing considerada, por esses clientes, como a mais eficiente.

Tomando como base as respostas inseridas nos dois questionários, pode-se inferir se as expectativas e percepções desses lojistas vão de encontro com a de seus clientes, e vice-versa.

\section{Caracterização Do Grupo}

O grupo de empresas entrevistadas foi formado por quatro empresas sediadas na região Sul Fluminense e capital do Estado do Rio de Janeiro, com tempo de atuação na internet de seis meses a oito anos, trabalhando com vendas de produtos e serviços diversos.

O grupo de clientes entrevistados foi formado por quinze clientes dessas mesmas empresas, previamente entrevistadas, com idades entre 19 e 48 anos, todos do gênero masculino e residentes em cidades do Sul Fluminense.

\section{Cenário Do Estudo}

Os questionários foram elaborados utilizando a ferramenta Google Forms, e encaminhados através de grupos de WhatsApp ou diretamente aos empresários e permaneceram disponíveis para resposta durante o 


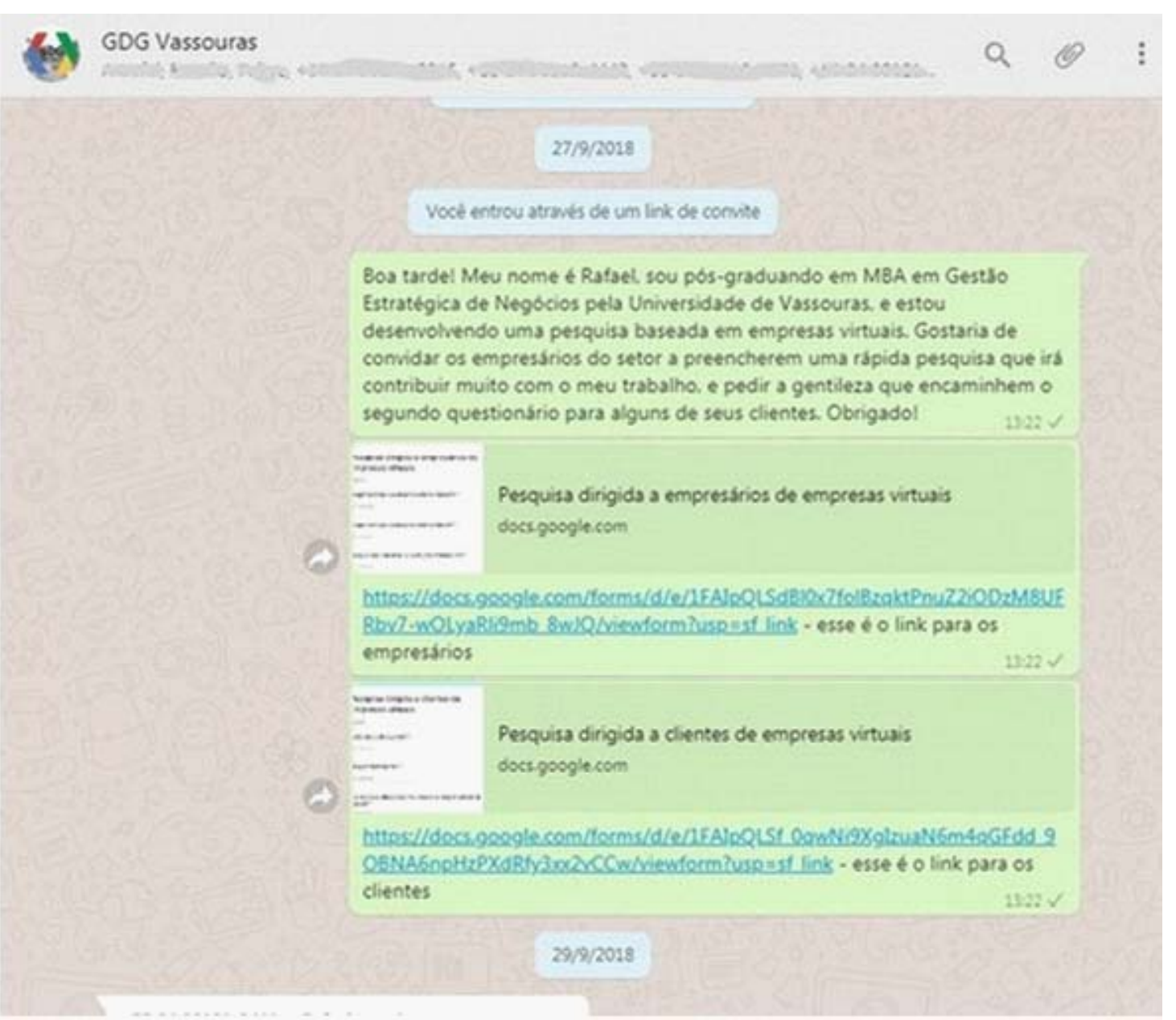

Figura 9. Exemplo do envio de link dos formulários em grupos do WhatsApp

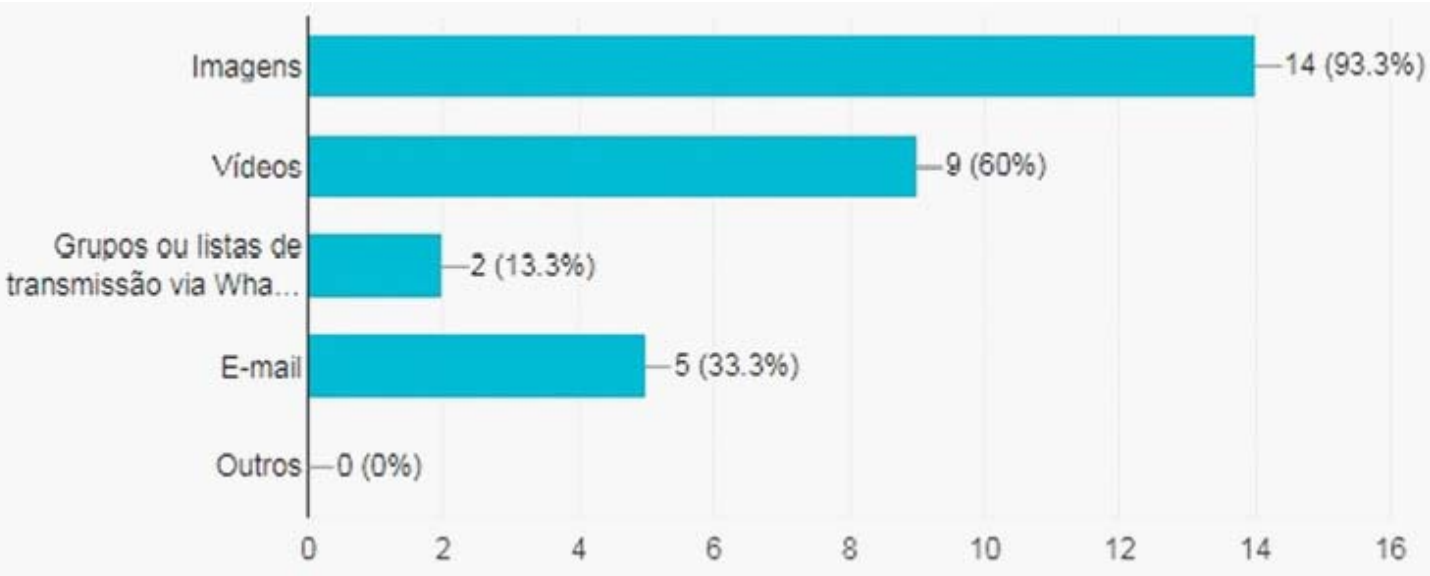

Figura 10. Ações de marketing consideradas mais eficientes por clientes 
período de 24 de Setembro de 2018 a 08 de Outubro de 2018.

Os formulários encontram-se disponíveis nos seguintes links: (i) formulário para os empresários em: https://goo.gl/yEGQ8Be (ii) o formulário para os clientes em: https://goo.gl/TtxZcP.

A figura 9 apresenta um exemplo de envio dos links dos formulários em um grupo no WhatsApp como exemplo.

\section{Fontes De Evidências}

Foram utilizados como fontes de evidências as próprias respostas inseridas nos formulários e os gráficos automaticamente criados pela ferramenta Google Forms. Os resultados e análise feita pelo autor do estudo são apresentados na seção seguinte.

\section{Resultados e Discussão}

Através das respostas coletadas, puderam ser identificadas como ferramentas e estratégias de divulgação das marcas por parte dos lojistas o marketing em redes sociais, o marketing Adwords, a indicação de clientes e pessoas do ramo, todas as opções com uma resposta cada. Uma das respostas inseridas foi respondida como "diversas", o que acabou não colaborando de forma objetiva para o estudo, por ser uma resposta muito vaga. Ao disponibilizar aos clientes a possibilidade de responder a respeito das ações de marketing que julgam funcionar melhor com eles, 93,3\% disseram prestar mais atenções a imagens, enquanto $60 \%$ disseram assistir a vídeos, 33,3\% olham e-mails e $13,3 \%$ preferem listas de transmissão ou grupos em WhatsApp. O marketing em redes sociais de fato tornase uma alternativa interessante, já que possibilita tanto o uso de imagens como de vídeos. A figura 10 apresenta uma visão geral das ações de marketing consideradas mais eficientes pelos clientes.

Como diferencial competitivo, foram identificados da parte dos lojistas o crescimento e facilidade do poder de compra, produtos únicos no mercado, menor burocracia e agilidade e novidades e produtos mais simples que não estão no foco das grandes empresas. Já em relação aos clientes, foram citados a credibilidade, custo do produto, variedade, novidades, praticidade, tempo, facilidade de escolha sem assédio de vendedores, tempo de entrega, comentários positivos de outros compradores. Sendo que dentre todas as respostas, 53\% relacionam-se ao preço do produto. Ou seja, dentre o universo dos lojistas entrevistados, somente um deles identificou um fator relacionado ao preço do produto como sendo sua vantagem competitiva. Esse resultado indica que os empresários que pretendem iniciar uma nova empresa no ambiente virtual, precisam estar atentos à questão do custo dos produtos e serviços ofertados, e ter essa questão como meta de consolidação de seus negócios no mercado.

Não foram identificadas desvantagens competitivas dessas empresas nesse estudo, visto que as mesmas conseguem ofertar uma grande variedade de produtos e serviços, atendendo a públicos diversos e todas mesmo quando localizadas fisicamente em cidades do interior, conseguem atender a clientes fora de sua região e ainda num raio de alcance acima de 500 $\mathrm{km}$.

Dentre os produtos mais buscados o mais citado foi roupas, por $60 \%$ dos entrevistados, seguido por informática, livros, sapatos e eletrônicos, todos com $20 \%$ das respostas. Também foram citados por $13 \%$ dos entrevistados os itens tecnologia e jogos de videogame. Por último, foram citados os itens perfumes, colecionáveis e importados, todos por apenas um dos entrevistados.

As respostas dadas a respeito de produtos procurados e não encontrados não permitiu identificar mercados não explorados no ambiente virtual, visto que foram citados os itens cartola, que numa rápida busca no Google foi encontrada e artigos colecionáveis, que também são possíveis de encontrar.

Dentre os itens considerados mais importantes por parte dos clientes em uma loja virtual, destacam-se a entrega rápida, com $86,7 \%$ das respostas, seguida por segurança na navegação e pagamento $(80 \%)$, diferentes formas de pagamento e frete barato $(73,3 \%)$, variedade de produtos $(66,7 \%)$, produtos inovadores $(46,7 \%)$, produtos de marcas conhecidas (33,3\%), e por último produtos personalizados (13,3\%).

A Figura 11 apresenta os itens considerados os mais importantes em uma loja virtual pelos clientes entrevistados.

Respondendo às hipóteses enumeradas na introdução deste artigo, confirmou-se a questão de possuir uma boa logística e entrega rápida como um dos principais fatores de sucesso desses negócios, visto que foi o item mais citado pelos consumidores. Já no tocante a variedade de produtos como uma vantagem competitiva, embora $66,7 \%$ dos consumidores tenham citado como um dos itens mais importantes em uma loja virtual, quando se trata de uma nova concorrente que é o foco deste estudo contra uma loja tradicional, essa questão não parece essencial, visto que foi citada por apenas dois clientes.

Em relação ao nível de burocracia para legalizar o negócio, o estudo indica que nos últimos dois anos a burocracia diminuiu, pois as duas empresas mais jovens participantes foram as que levaram menos tempo para legalizarem ( 1 ano - 3 meses e 2 anos imediato), ao passo que as mais antigas foram as que levaram mais tempo (8 anos - quase 5 anos e 3 anos - 5 anos). Ao serem perguntados a respeito da dificuldade 


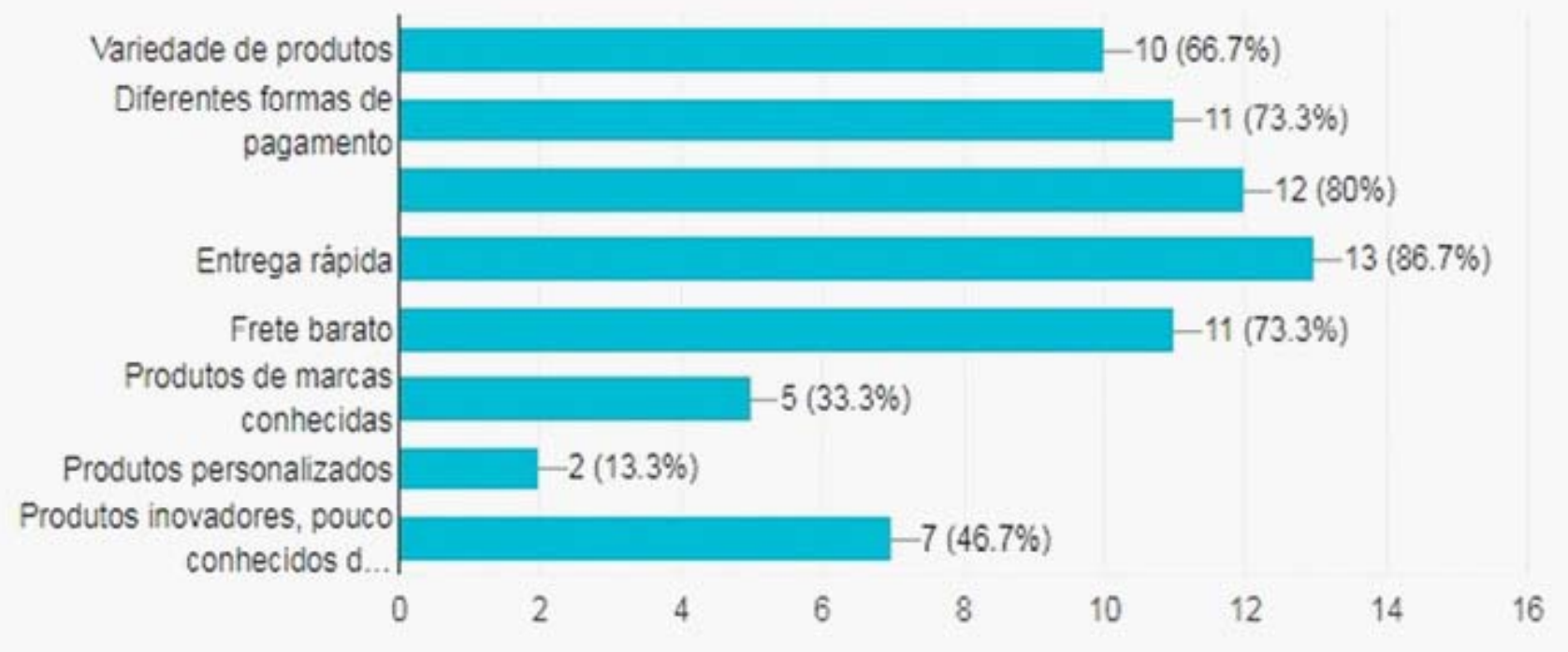

Figura 11. Itens considerados mais importantes em uma loja virtual por seus clientes

de gestão, foi disponibilizada uma escala de 1 a 5 , em que 1 indicava o nível mais fácil e 5 o mais difícil. Nenhum dos entrevistados considerou a escala 1 , sendo que dois deles consideraram o nível 4, o que leva a inferir que embora haja um baixo nível de burocracia na legalização, isso não se converte em facilidade de gestão desses negócios.

Possuir produtos personalizados não foi identificado como diferencial competitivo, visto que não foi citado por nenhum dos entrevistados, e no tocante a itens essenciais em uma loja virtual foi citado por apenas 13,3\% dos entrevistados.

A respeito das ações de pós-venda, $75 \%$ dos lojistas entrevistados disseram fazê-las, o que comprova sua importância e a conscientização dos mesmos em relação a essa estratégia para consolidação das suas marcas junto aos clientes.

Os resultados obtidos vão de encontro ao que diz Casagrande, (2018) em relação aos sete pontos de sucesso para as vendas digitais, bem como nasquestões observadas ao longo da pesquisa E-commerce Trends e no Relatório Webshoppers 2019.

\section{Considerações Finais}

O presente estudo buscou analisar o mercado de empresas virtuais no Brasil e no tocante a novas e pequenas empresas do setor, observar as estratégias de marketing para consolidação de suas marcas junto aos consumidores, verificando também se estas estão de acordo com as expectativas de seus clientes. Isso foi possível através das respostas obtidas por parte de empresários do setor e clientes dessas mesmas empresas.

Destaca-se a importância de ter preços competitivos como um dos principais fatores de sucesso para essas empresas, embora os empresários entrevistados em grande parte não tenham considerado essa questão. Também relacionado ao preço do produto, desenvolver uma estratégia de frete barato e entrega rápida, também demonstraram ser questões essenciais a serem trabalhadas. Destaca-se também como ferramenta de marketing mais utilizada e mais eficiente segundo os próprios consumidores o marketing nas redes sociais.

Houve certa dificuldade em localizar outras empresas, visto que o estudo foi realizado no âmbito da região sul-fluminense do estado do Rio de Janeiro, e não existe ferramenta devidamente configurada para localizar essas empresas por suas localizações físicas, o que acabou limitando o estudo.

Como possíveis trabalhos futuros, podemos citar um estudo voltado às dificuldades encontradas na gestão dos negócios online visto que a hipótese de facilidade frente à baixa burocracia na legalização desses negócios não foi confirmada. Um estudo detalhado pode identificar quais são essas dificuldades encontradas, e propor soluções que venham de fato tornar simples a gestão das pequenas empresas virtuais no Brasil.

Por fim, acredita-se que através dos resultados obtidos e confrontando-os com os dados apresentados na fundamentação teórica, é possível obter um direcionamento em relação às estratégias mais eficientes de consolidação de uma nova marca no ambiente virtual, contribuindo assim com o sucesso desses negócios, bem como com a satisfação das expectativas dos consumidores.

\section{Referências}

ARAUJO, José Braz de; ZILBER, Silvia Novaes. Adoção de E-Business e mudanças no modelo de negócio: inovação organizacional em pequenas 
empresas dos setores de comércio e serviços. Gestão \& Produção, v. 20, n. 1, p. 147-161, 2013.

CASAGRANDE, M. O cliente no centro do consumo. Gestão e Negócios, n. 115, p. 71-74, setembro 2018.

CASAGRANDE, M. Sucesso nas vendas digitais. Gestão e Negócios, n. 115, p. 46-50, setembro 2018.

DE ALMEIDA, Viana et al. Os Impactos das Reclamações On-line na Lealdade dos Consumidores: um Estudo Experimental. RAC-Revista de Administração Contemporânea, v. 16, n. 5, 2012.

NASCIMENTO, Rafael Moraes do. E-commerce no Brasil: perfil do mercado e do e-consumidor brasileiro. 2011. Tese de Doutorado.

PAZERA, A. Assuntos em alta no fórum e-commerce Brasil 2017. Disponível em: <https://www.ecommercebrasil.com.br/artigos/assuntos-forum-ecommerce/>. Acesso em: 09 set. 2018.

PESQUISA e-commerce trends 2017 - Panorama de mercado. Disponível em: <http://blog.shoppub.com.br/pesquisa-e-commerce-trends-2017/>. Acesso em: 09 set. 2018.

RELATÓRIO Webshoppers 2019. Disponível em: <https://blog.netzee.com. br/relatorio-webshoppers-39/>. Acesso em 10 set. 2019.

PESSOA, L. Como se adaptar às mudanças do consumidor futuro. Disponível em: <https://www.linkedin.com/pulse/como-se-adaptar-\%C3\%A0smudan\%C3\%A7as-do-consumidor-futuro-lorrayne-pessoa/?trk=eml-email feed_ecosystem_digest_01-recommended_articles-3-Unknown\&midToke n=AQHrVnMCvy0Vuw\&fromEmail=fromEmail\&ut=1stQXr67e8zEs1>. Acesso em: 11 out. 2018. 